\title{
Association between indices of prosthesis internal orifice size and operative mortality after isolated aortic valve replacement
}

\author{
Charles R. Bridges, MD, ScD, ${ }^{\text {a }}$ Sean M. O'Brien, PhD, Joseph C. Cleveland, MD, ${ }^{\mathrm{c}}$ Edward B. Savage, MD, ${ }^{\mathrm{d}}$
} James S. Gammie, MD, ${ }^{\mathrm{e}}$ Fred H. Edwards, MD, ${ }^{f}$ Eric D. Peterson, MD, ${ }^{\mathrm{b}}$ and Frederick L. Grover, $\mathrm{MD}^{\mathrm{c}}$

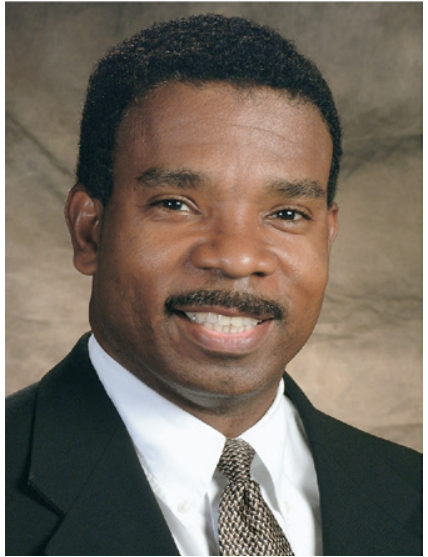

Dr Bridges

Earn CME credits at http:// cme.ctsnetjournals.org

Supplemental material is available online.
Objectives: The appropriate index of prosthesis internal orifice size and its effect on operative mortality after aortic valve replacement are controversial. We examined the association between several relevant indices and patient size on operative mortality. Indices examined included projected in vivo effective orifice area and geometric orifice area, with patient size defined as body surface area.

Methods: A review of the Society of Thoracic Surgeons National Cardiac Database (2000-2004) yielded 48,722 patients who had isolated aortic valve replacement This analysis is based on the cohort of 42,310 patients with the 8 most prevalent valve types with manufacturer's labeled sizes $19 \mathrm{~mm}$ through $29 \mathrm{~mm}$. Multivariable logistic regression models were employed to determine the effects of body surface area, effective orifice area, geometric orifice area, and selected derived indices (eg, effective orifice area/body surface area) on risk-adjusted operative mortality.

Results: In separate multivariable models, effective orifice area and geometric orifice area were both inversely correlated with operative mortality. However, an unanticipated finding was that with either effective orifice area or geometric orifice area held constant, body surface area was significantly and inversely correlated with operative mortality. When patients were stratified by effective orifice area, geometric orifice area, or manufacturer's labeled valve size and type, elevations in body surface area were associated with a decrease rather than an increase in operative mortality.

Conclusions: Prostheses with small geometric orifice area or small effective orifice area are associated with increased operative mortality after isolated aortic valve replacement. Even for valves with small effective orifice area, however, mortality decreases as body surface area increases. With respect to operative mortality, therefore, our results do not support using arbitrary cutoff values of effective orifice area/body surface area to determine the valve to utilize in a given patient.

From the Departments of Surgery and Bioengineering, ${ }^{a}$ the University of Pennsylvania Health System, Philadelphia, Pa; Duke Clinical Research Institute, ${ }^{\mathrm{b}}$ Durham, NC; Department of Surgery, ${ }^{\mathrm{c}}$ University of Colorado, Denver, Colo; Department of Cardiovascular-Thoracic Surgery, ${ }^{\mathrm{d}}$ Rush University, Chicago, Ill; Department of Surgery, e University of Maryland Medical Center, Baltimore, Md; and Department of Surgery, ${ }^{\mathrm{f}}$ University of Florida, Jacksonville, Fla.

The Society of Thoracic Surgeons through the Adult National Cardiac Database and the Duke Clinical Research Institute supported this work.

Read at the Eighty-fifth Annual Meeting of The American Association for Thoracic Surgery, San Francisco, Calif, April 10-13, 2005

Received for publication April 8, 2005; revisions received Nov 1, 2006; accepted for publication Nov 16 2006

Address for reprints: Charles R. Bridges, MD, ScD, Department of Surgery, the University of Pennsylvania Health System, Department of Surgery, 4 Silverstein, Hospital of the University of Pennsylvania, Philadelphia, PA 19104 (E-mail: cbridges@pahosp.com).

J Thorac Cardiovasc Surg 2007;133:1012-21

$0022-5223 / \$ 32.00$

Copyright (C) 2007 by The American Association for Thoracic Surgery

doi:10.1016/j.jtcvs.2006.11.028 


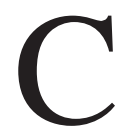

ontroversy exists regarding the importance of patient size and prosthesis internal orifice size on both early and late mortality after aortic valve replacement (AVR) surgery. ${ }^{1-16}$ We can summarize the controversy as revolving around 4 key issues: (1) How do we define the most hemodynamically relevant index of aortic prosthesis internal orifice size? (2) However defined, is an appropriate, calculable, or measurable index of internal aortic prosthesis size an independent predictor of short-term or long-term morbidity and mortality after AVR? (3) What is the nature of the interaction between the defined index and patient size as predictors of operative mortality? (4) How should the conduct of AVR surgery be influenced-including the selection of an aortic prosthesis for a given patient-by considerations related to patient size and an appropriate index of prosthesis internal orifice size?

The term prosthesis-patient mismatch was first coined by Rahimtoola ${ }^{1}$ and has been used extensively in the literature to describe the use of a prosthesis of a given type that is "too small" for a patient of a given size. He defined it to occur when "the effective prosthetic valve area, after insertion into the patient, is less than that of a normal human valve." ${ }^{1}$ We now know that with the possible exception of aortic homografts and pulmonary autografts, all bioprosthetic and all mechanical valves are associated with some degree of mismatch by this definition. ${ }^{3,16}$ As outlined above, controversy exists as to the most hemodynamically relevant index of prosthesis internal orifice size. It is well appreciated that a manufacturer's labeled valve size (eg, 19 $\mathrm{mm}, 21 \mathrm{~mm}$, etc) is not consistently defined across different manufacturers. ${ }^{17,18}$ For any given manufacturer, the internal orifice diameter is always less than the manufacturer's labeled size. Marked differences in internal orifice area (equivalent to geometric orifice area $[\mathrm{GOA}]$ ) and external diameter exist by manufacturer for mechanical, stented, and stentless bioprostheses. For aortic homografts, the manufacturer's labeled size is equal to the internal orifice diameter, and for the Toronto stentless porcine valve (St Jude Medical, Minneapolis, Minn) and the Medtronic Hall valve (Medtronic, Minneapolis, MN), it is equal to the external diameter of the valve; for most other mechanical valves, the external diameter is 3 to $5 \mathrm{~mm}$ larger than the manufacturer's labeled size. ${ }^{17,18}$

As a result of this confusing nomenclature, most studies that have attempted to relate prosthesis internal orifice size to long-term or short-term mortality have eschewed the use of manufacturer's labeled valve size as a covariate as it is not a robust predictor (across different valve types and manufacturers) of the functional relationship between pressure gradient and flow for a given aortic valve prosthesis. Rather, indices of prosthesis internal orifice size such as the projected in vivo effective orifice area (EOA) or GOA have been utilized. ${ }^{3-10,15}$ More recently, GOA/body surface area

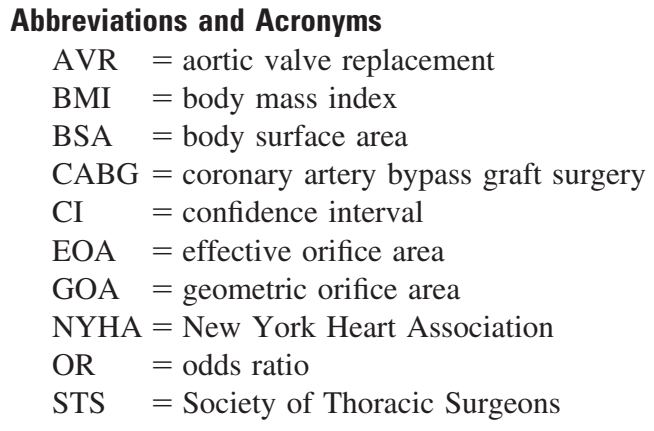

(BSA) has been proposed as an index of prosthesis internal orifice size ${ }^{3-5}$ Using GOA/BSA as an index of prosthesis internal orifice size, Blackstone and colleagues ${ }^{3}$ found that GOA/BSA was not a significant independent predictor of intermediate-term survival and that for mechanical valves but not for bioprosthetic valves, GOA/BSA was a significant but weak predictor of 30-day mortality. In contrast, Blais and colleagues ${ }^{6}$ found that EOA indexed by BSA (EOA/BSA) was a robust multivariable predictor of operative mortality and that patients with EOA/BSA $<0.65$ $\mathrm{cm}^{2} / \mathrm{m}^{2}$ had an odds ratio (OR) of 11.4 (4.4-29.5) for operative mortality compared with those with EOA/BSA > $0.85 \mathrm{~cm}^{2} / \mathrm{m}^{2}$. Furthermore, these authors argue that EOA (projected or estimated in vivo) rather than GOA is the most hemodynamically relevant preoperative index of prosthesis internal orifice size because it is more highly correlated with pressure gradients that occur during left ventricular ejection. ${ }^{7,8,19}$ These considerations notwithstanding, others ${ }^{3-5}$ have argued that because actual (rather than projected) in vivo EOA varies with exercise, aortic anatomy, and hemodynamics, ${ }^{20-24}$ GOA is a more robust index of hemodynamically relevant prosthesis internal orifice size.

Here, in contrast to previous studies, ${ }^{3-10,15}$ we do not decide a priori which index of internal prosthesis orifice size to utilize. Rather, we used multivariable models with data derived from the Society of Thoracic Surgeons (STS) National Cardiac Database to assess the significance of both projected in vivo EOA and GOA as independent predictors of operative mortality after isolated AVR. We also determine the independent predictive value of BSA as well as selected indices derived from rational combinations of EOA or GOA and BSA (eg, EOA/BSA) on operative mortality.

\section{Materials and Methods STS Database}

The STS National Cardiac Database was established in 1989 to report surgical outcomes following cardiothoracic surgical procedures. ${ }^{25}$ Sites enter patient data using uniform definitions (available online at http://www.sts.org) and certified software systems. Although participation in the STS database is voluntary, data com- 
pleteness is high, with overall preoperative risk factors missing in fewer than $5 \%$ of submitted cases. The accuracy of submitted cases has been confirmed in independent comparison of hospital coronary artery bypass graft surgery $(\mathrm{CABG})$ volume and mortality rates reported to the STS versus those reported to Centers for Medicare and Medicaid Services. ${ }^{26}$

\section{Patient Population}

Patients in the STS adult cardiac database who had isolated aortic valve replacement surgery with a prosthetic valve from January 1, 2000 to December 31, 2004 were considered for inclusion in the study. Patients having concomitant procedures such as multiplevalve or CABG surgery were excluded, leaving 48,722 patients. The analysis was further restricted to 42,880 patients receiving 1 of the 8 most prevalent valve types in the database (mechanical prostheses: Carbomedics (Austin, Tex), Medtronic-Hall, St Jude Medical; stented bioprostheses: Carpentier-Edwards Pericardial (Edwards Life Sciences, Irvine, Calif), Hancock II Porcine (Medtronic), Medtronic Mosaic Porcine; stentless porcine prostheses: Medtronic, Toronto SPV) and the 6 most prevalent manufacturers' labeled sizes (19 mm, $21 \mathrm{~mm}, 23 \mathrm{~mm}, 25 \mathrm{~mm}, 27 \mathrm{~mm}, 29 \mathrm{~mm}$ ). We excluded the small minority of valves with even manufacturer's labeled sizes from the analysis. Patients with status coded as "salvage" were excluded ( $\mathrm{n}=$ 45) as well as subjects with missing data on 6 key variables (age, gender, BSA, body mass index [BMI], height, and weight), leaving a sample of 42,310 patients in 646 hospitals. Patients who received a valve for which EOA or GOA data were unavailable were excluded from multivariable models utilizing that variable. Patient characteristics are summarized in Table 1. Missing values are excluded.

\section{Indices of Prosthesis Internal Orifice Size and Patient Size}

All estimates of projected in vivo EOA and most estimates of GOA were also obtained from the literature, and other estimates of GOA were obtained directly from the manufacturers (Table 2). Most of the projected EOA values taken from the literature were derived by performing Doppler imaging studies on patients who had undergone aortic valve replacement surgery and then calculating the average Doppler-estimated EOA among patients having the same prosthesis model and label size. Estimates of EOA were available for all but 5 of the 48 manufacturers' labeled valve-sizemodel combinations included in the analysis, and estimates of GOA were available for all but one manufacturer's labeled valvesize-model combination.

BSA was estimated for each patient using the Dubois and Dubois formula ${ }^{27}$ : BSA $\left(\mathrm{m}^{2}\right)=0.007184 \times$ height $(\mathrm{cm})^{0.725} \times$ weight $(\mathrm{kg})^{0.425}$.

\section{Clinical End Point}

The primary end point, operative mortality, is defined as death during the same hospitalization as surgery or after discharge but within 30 days of surgery. Additional data definitions are available at www.sts.org.

\section{Multivariable Analyses}

Several logistic regression models were developed to assess the association between surrogates of patient size (BSA) and prosthesis internal orifice size (EOA or GOA) and operative mortality while adjusting for covariates. In the first set of analyses, variables relating to patient size and prosthesis internal orifice size included: $\mathrm{EOA}, \mathrm{EOA}^{2}, 1 / \mathrm{BSA}, 1 / \mathrm{BSA}^{2}, \mathrm{EOA} / \mathrm{BSA}, \mathrm{EOA}^{2} / \mathrm{BSA}^{2}$. We also performed parallel analyses by substituting GOA for EOA in the list of variables. The quadratic terms $\left(\mathrm{EOA}^{2}\right.$ or $\left.\mathrm{GOA}^{2}\right)$ allow the estimated relationship between prosthesis internal orifice size and mortality to be nonlinear on the log-odds scale. The ratio terms $\mathrm{EOA} / \mathrm{BSA}$ and $\mathrm{EOA}^{2} / \mathrm{BSA}^{2}$ (or GOA/BSA and $\mathrm{GOA}^{2} / \mathrm{BSA}^{2}$ ) allow the shape of the relationship between prosthesis internal orifice size and mortality to depend on the patient's body size. Conversely, these ratio terms allow the shape of the relationship between BSA and mortality to depend on the valve's estimated internal orifice size. We also fit these models without including the ratio terms to estimate the average association between internal orifice size and mortality averaging over body size. Additional variables in each model were: patient age (modeled as a 2-phase linear function with a change of slope at 75 years), diabetes, renal failure, dialysis, hypertension, cerebrovascular accident, infective endocarditis, chronic lung disease, peripheral vascular disease, reoperation, New York Heart Association (NYHA) class IV, pulmonary hypertension, myocardial ischemia within 3 weeks, status (elective, urgent, emergent), preoperative intra-aortic balloon pump, gender, ejection fraction less than 40, aortic stenosis, aortic insufficiency, congestive heart failure, cerebrovascular disease, arrhythmia, nonwhite race, obesity (BMI $>35 \mathrm{~kg} / \mathrm{m}^{2}$ ), and year of surgery. An assumption of the model (made for simplicity) is that valve-related variables do not interact with patient factors other than BSA. We tested this assumption and found that it did not have a significant impact on the results. Substituting BSA for 1/BSA in the regression models also had little impact on the results.

Inferences about the association between indices of prosthesis internal orifice size and mortality are potentially confounded by several factors including: (1) unmeasured intrinsic valve characteristics peculiar to each valve model and (2) measurement error in the assessment of a valve's projected EOA or GOA. Two different approaches were used to adjust for these sources of confounding. First, we fit the logistic regression models by including fixed-effect indicator variables for each valve model. This approach adjusts for any valve-related factors that might impact mortality through mechanisms unrelated to the valve's internal orifice size. This is appropriate because the risk of mortality could potentially vary by valve model, even among valve models having the same internal orifice size. In these analyses, parameters describing the "effect" of EOA or GOA on mortality pertain to differences in manufacturers' labeled valve size when the valve model is held constant. Second, we fit random effects logistic regression models that included random effects for each combination of manufacturer model and labeled size. The inclusion of random effects allows for an unobserved valve-level component specific to each combination of model and label size. These random effects capture any valve-level factors that were omitted from the model that might systematically increase or decrease the risk of mortality among patients receiving the same valve model and label size. In addition, this approach accounts for potential measurement error in the estimation of average EOA and GOA by subsuming the true EOA and GOA values into the random effects component. The results of both modeling approaches were similar with respect to both point estimates and confidence intervals (CIs). For brevity, only the 
TABLE 1. Patient characteristics

\begin{tabular}{|c|c|c|}
\hline \multirow[b]{2}{*}{ Characteristic } & \multicolumn{2}{|c|}{ Totals } \\
\hline & $\mathbf{n}$ & Percentage \\
\hline M & 24,479 & 57.86 \\
\hline $\mathrm{F}$ & 17,831 & 42.14 \\
\hline \multicolumn{3}{|l|}{ Race } \\
\hline White & 37,284 & 88.95 \\
\hline Black & 2069 & 4.94 \\
\hline Other & 2562 & 6.12 \\
\hline \multicolumn{3}{|l|}{ Age (y) } \\
\hline$<40$ & 1813 & 4.29 \\
\hline $40-49$ & 3553 & 8.40 \\
\hline $50-59$ & 6439 & 15.22 \\
\hline $60-69$ & 9600 & 22.69 \\
\hline $70-79$ & 13,946 & 32.96 \\
\hline$\geq 80$ & 6959 & 16.45 \\
\hline \multicolumn{3}{|l|}{ BMI } \\
\hline $18-24$ & 11,644 & 27.85 \\
\hline $25-29$ & 15,420 & 36.89 \\
\hline $30-34$ & 8677 & 20.75 \\
\hline$\geq 35$ & 6069 & 14.51 \\
\hline \multicolumn{3}{|l|}{ BSA } \\
\hline$<1.50$ & 1558 & 3.68 \\
\hline $1.50-1.74$ & 8921 & 21.08 \\
\hline $1.75-1.99$ & 15,867 & 37.50 \\
\hline $2.00-2.24$ & 11,915 & 28.16 \\
\hline $2.25-2.49$ & 3387 & 8.01 \\
\hline$\geq 2.50$ & 662 & 1.56 \\
\hline \multicolumn{3}{|l|}{ Ejection fraction } \\
\hline$<30$ & 2223 & 5.86 \\
\hline $30-39$ & 3164 & 8.36 \\
\hline $40-49$ & 5118 & 13.52 \\
\hline$\geq 50$ & 27,371 & 72.26 \\
\hline \multicolumn{3}{|l|}{ Valve type } \\
\hline Mechanical & 13,653 & 32.27 \\
\hline Stented bio & 25,640 & 60.60 \\
\hline Stentless bio & 3017 & 7.13 \\
\hline \multicolumn{3}{|l|}{ Mechanical valve } \\
\hline No & 28,657 & 67.73 \\
\hline Yes & 13,653 & 32.27 \\
\hline \multicolumn{3}{|l|}{ Valve model } \\
\hline CarboMedics Mechanical & 2398 & 5.67 \\
\hline St Jude Medical Mechanical & 10,636 & 25.14 \\
\hline Carpentier-Edwards Perimount & 18,776 & 44.38 \\
\hline Medtronic Hall Mechanical & 619 & 1.46 \\
\hline Hancock II Porcine & 2721 & 6.43 \\
\hline Medtronic Freestyle Stentless & 1845 & 4.36 \\
\hline Medtronic Mosaic Porcine & 4143 & 9.79 \\
\hline St Jude Medical-Toronto SPV Stentless & 1172 & 2.77 \\
\hline \multicolumn{3}{|l|}{ Manufacturer's labeled valve size (mm) } \\
\hline 19 & 4107 & 9.71 \\
\hline 21 & 11,700 & 27.65 \\
\hline 23 & 13,172 & 31.13 \\
\hline 25 & 8511 & 20.12 \\
\hline 27 & 3691 & 8.72 \\
\hline 29 & 1129 & 2.67 \\
\hline Aortic stenosis & 33,978 & 80.74 \\
\hline
\end{tabular}

TABLE 1. Continued

\begin{tabular}{|c|c|c|}
\hline \multirow[b]{2}{*}{ Characteristic } & \multicolumn{2}{|c|}{ Totals } \\
\hline & $\mathbf{n}$ & Percentage \\
\hline \multicolumn{3}{|l|}{ Aortic insufficiency } \\
\hline None & 15,601 & 37.93 \\
\hline Trivial & 3538 & 8.60 \\
\hline Mild & 5632 & 13.69 \\
\hline Moderate & 5703 & 13.87 \\
\hline Severe & 10,655 & 25.90 \\
\hline Reoperation & 7083 & 16.81 \\
\hline Previous cardiovascular intervention & 9255 & 21.91 \\
\hline Congestive heart failure & 16,635 & 39.46 \\
\hline Myocardial infarction & 3706 & 8.78 \\
\hline Cardiogenic shock & 289 & 0.68 \\
\hline Resuscitation & 168 & 0.40 \\
\hline \multicolumn{3}{|l|}{ NYHA class } \\
\hline I & 6442 & 16.09 \\
\hline II & 11,096 & 27.72 \\
\hline III & 16,813 & 41.99 \\
\hline IV & 5690 & 14.21 \\
\hline \multicolumn{3}{|l|}{ Status } \\
\hline Elective & 33,714 & 79.81 \\
\hline Urgent & 8129 & 19.24 \\
\hline Emergent & 399 & 0.94 \\
\hline Diabetes & 8512 & 20.17 \\
\hline Renal failure & 2527 & 5.99 \\
\hline Dialysis & 859 & 2.04 \\
\hline Hypertension & 26,431 & 62.64 \\
\hline Hypercholesterolemia & 18,028 & 42.84 \\
\hline Previous cerebrovascular accident & 2803 & 6.64 \\
\hline Peripheral vascular disease & 4816 & 11.41 \\
\hline Preoperative arrhythmia & 6688 & 15.85 \\
\hline Infectious endocarditis & 2123 & 5.03 \\
\hline
\end{tabular}

NYHA, New York Heart Association.

fixed effect analyses are presented. These analyses were first performed using all patients in the study population and were subsequently repeated in the subpopulation of patients having BMI $<30$ and in patients who received manufacturers' labeled valve sizes 19 or 21 .

We summarized the results of the multivariable models by presenting ORs along with their asymptotic 95\% CIs. These ORs describe the relative increase or decrease in the estimated odds of mortality as a function of valve internal orifice size (EOA or GOA) compared with a reference size of $\mathrm{EOA}=2.0 \mathrm{~cm}^{2}$ or $\mathrm{GOA}=5.0$ $\mathrm{cm}^{2}$. We also displayed the model results graphically, by plotting estimated mortality risk as a function of valve internal orifice size (EOA or GOA) and body size (BSA). For these plots, "riskadjusted mortality" is defined as the predicted probability of mortality for a patient having the indicated values of EOA or GOA and BSA and a hypothetical baseline risk of mortality loosely corresponding to "average risk." The baseline risk was determined by requiring that the average risk-adjusted mortality rate (obtained by averaging across all of the observed values of EOA, GOA, and BSA in the study population) be equal to the observed mortality rate in the study population. 
TABLE 2. Estimated EOA and GOA by valve model and size

\begin{tabular}{|c|c|c|c|c|c|c|}
\hline & \multicolumn{6}{|c|}{ Estimated EOA $\left(\mathrm{cm}^{2}\right)$} \\
\hline & $19 \mathrm{~mm}$ & $21 \mathrm{~mm}$ & $23 \mathrm{~mm}$ & $25 \mathrm{~mm}$ & $27 \mathrm{~mm}$ & $29 \mathrm{~mm}$ \\
\hline M1 & $1.00^{28}$ & $1.54^{28}$ & $1.63^{28}$ & $1.98^{28}$ & $2.41^{28}$ & $2.63^{28}$ \\
\hline M2 & N/A & $1.25^{33}$ & $1.56^{33}$ & $2.17^{33}$ & $2.11^{33}$ & $2.25^{33}$ \\
\hline M3 & $1.04^{29}$ & $1.38^{29}$ & $1.52^{29}$ & $2.08^{29}$ & $2.65^{29}$ & $3.23^{29}$ \\
\hline B1 & $1.10^{30}$ & $1.30^{30}$ & $1.50^{30}$ & $1.80^{30}$ & $1.80^{30}$ & N/A \\
\hline B2 & $\mathrm{N} / \mathrm{A}$ & $1.18^{34}$ & $1.33^{34}$ & $1.46^{34}$ & $1.55^{34}$ & $1.60^{34}$ \\
\hline B3 & $1.20^{31}$ & $1.22^{31}$ & $1.38^{31}$ & $1.65^{31}$ & $1.8^{31}$ & $2.0^{31}$ \\
\hline S1 & $1.15^{32}$ & $1.35^{32}$ & $1.48^{32}$ & $2.00^{32}$ & $2.32^{32}$ & $\mathrm{~N} / \mathrm{A}$ \\
\hline \multirow[t]{3}{*}{ S2 } & $\mathrm{N} / \mathrm{A}$ & $1.30^{*}$ & $1.49^{*}$ & $1.70^{*}$ & $2.00^{*}$ & $2.50^{*}$ \\
\hline & \multicolumn{6}{|c|}{ Estimated GOA $\left(\mathrm{cm}^{2}\right)$} \\
\hline & $19 \mathrm{~mm}$ & $21 \mathrm{~mm}$ & $23 \mathrm{~mm}$ & $25 \mathrm{~mm}$ & $27 \mathrm{~mm}$ & $29 \mathrm{~mm}$ \\
\hline M1 & $1.70^{17}$ & $2.19^{17}$ & $2.69^{17}$ & $3.30^{17}$ & $3.98^{17}$ & $\mathrm{~N} / \mathrm{A}$ \\
\hline M2 & $\mathrm{N} / \mathrm{A}$ & $2.01^{17}$ & $2.54^{17}$ & $3.14^{17}$ & $3.80^{17}$ & $4.52^{17}$ \\
\hline M3 & $1.70^{17}$ & $2.19^{17}$ & $2.69^{17}$ & $3.27^{17}$ & $3.91^{17}$ & $4.56^{17}$ \\
\hline B1 & $2.54^{17}$ & $3.14^{17}$ & $3.80^{17}$ & $4.52^{17}$ & $5.31^{17}$ & $6.16^{17}$ \\
\hline B2 & $2.09^{17}$ & $2.63^{17}$ & $3.20^{17}$ & $3.84^{17}$ & $4.12^{17}$ & $4.79^{17}$ \\
\hline B3 & $2.41^{*}$ & $2.69^{*}$ & $3.30^{*}$ & $3.98^{*}$ & $4.52^{*}$ & $5.31^{*}$ \\
\hline S1 & $2.01 *$ & $2.54^{*}$ & $3.14^{*}$ & $3.63^{*}$ & $4.34^{*}$ & $5.11^{* *}$ \\
\hline S2 & $1.77^{17}$ & $2.27^{17}$ & $2.84^{17}$ & $3.46^{17}$ & $4.15^{17}$ & $4.91^{17}$ \\
\hline
\end{tabular}

Mechanical prostheses: M1, Carbomedics; M2, Medtronic-Hall; M3, St. Jude Medical. Stented bioprostheses: B1, Carpentier-Edwards Pericardial; B2, Hancock II Porcine; B3, Medtronic Mosaic Porcine. Stentless porcine prostheses: S1, Medtronic; S2, Toronto SPV. Superscripts refer to the original reference sources (see also reference 3) $E O A$, effective orifice area; $G O A$, geometric orifice area; $N / A$, Not available. *Data provided by the manufacturer.

\section{Results}

\section{Patient Characteristics}

The characteristics of our patient population are summarized in Table 1. Fifty-eight percent of our patients were men, $89 \%$ were white, and most had a normal ejection fraction (72\% were greater than 50\%). Despite the relatively preserved left ventricular function, over $50 \%$ had significant

TABLE 3. Frequencies of valves in study population (labeled sizes 19, 21, 23, 25, 27, 29)

\begin{tabular}{lr}
\hline Valve & $\begin{array}{r}\text { Number of } \\
\text { patients (\%) }\end{array}$ \\
\hline M1 (Carbomedics Mechanical Prosthesis) & $2398(5.7)$ \\
M2 (Medtronic-Hall Mechanical Prosthesis) & $619(1.5)$ \\
M3 (St Jude Medical Mechanical Prosthesis) & $10,636(25.1)$ \\
B1 (Carpentier-Edwards Pericardial & $18,776(44.4)$ \\
Bioprosthesis) & \\
B2 (Hancock II Porcine Bioprosthesis) & $2721(6.4)$ \\
B3 (Medtronic Mosaic Porcine Bioprosthesis) & $4143(9.8)$ \\
S1 (Medtronic Freestyle Stentless Porcine) & $1845(4.4)$ \\
S2 (St Jude-Toronto SPV Stentless Porcine) & $1172(2.8)$ \\
Total & $42,310(100)$
\end{tabular}

Mechanical prostheses definitions in Table 2. heart failure symptoms (NYHA class III or IV). Hypertension was common (63\%); roughly one third of the valves implanted were mechanical and two thirds were tissue valves.

\section{Distribution of Valve Types}

In Tables 2 and 3 we summarize the GOA and EOA values used and the manufacturers and types of valves included in the analysis as well as their respective frequencies in the data set. St Jude Mechanical prostheses and Carpentier Edwards pericardial prostheses together represent $70 \%$ of the valves in the data set.

\section{Multivariable Analyses}

In separate parallel analyses, decreasing GOA and decreasing EOA compared with their respective reference values were both strongly associated with increasing operative mortality risk, regardless of the patient's body size (Tables 4 and 5, Figures 1 and 2). For average-sized patients $\left(\mathrm{BSA}=2.0 \mathrm{~m}^{2}\right)$, a decrease in EOA from $2.00 \mathrm{~cm}^{2}$ to $1.50 \mathrm{~cm}^{2}$ is associated with a $35 \%$ increase in the odds of mortality (OR $=1.35 ; 95 \%$ CI $[1.21,1.52])$, and a $0.75 \mathrm{~cm}^{2}$ decrease in EOA $\left(2.00 \mathrm{~cm}^{2}\right.$ vs $1.25 \mathrm{~cm}^{2}$ ) is associated with a $73 \%$ increase in the odds of mortality $(\mathrm{OR}=1.73 ; 95 \%$ CI $[1.42,2.11])$. Results were similar when GOA was used as an index of prosthesis internal orifice size. The estimated shape of the relationship between EOA (or GOA) and log-odds of mortality was generally similar regardless of the patient's body size (Figure 1). In multivariable models, we tested whether the interaction between BSA and valve size (as expressed as either EOA or GOA) was significant: it was not $(P=0.145$ for $\mathrm{BSA} / \mathrm{EOA}$ interaction, $2 \mathrm{df} ; P=0.2527$ for $\mathrm{GOA} / \mathrm{BSA}$ interaction, 2df; etc). As a result, we do not conclude that the relationship between GOA or EOA and mortality depends strongly on the BSA of the patients. Results did not change when the analysis was restricted to nonobese patients (BMI < 30) or patients with a "small" aortic annulus (manufacturers' labeled valve size 19 or 21; Tables E1 through E4).

Regardless of the EOA or GOA of the valve inserted, we found that operative mortality generally decreased with increasing BSA (Figures 1, 2, and 3). This implies that among patients receiving the same manufacturer's model

TABLE 4. Adjusted ORs for GOA at selected values of BSA

\begin{tabular}{lccc}
\hline & \multicolumn{3}{c}{$\mathbf{G O A}\left(\mathbf{c m}^{2}\right)$} \\
\cline { 2 - 4 } BSA & $\mathbf{4 . 0}$ vs $\mathbf{5 . 0}$ & $\mathbf{3 . 0}$ vs $\mathbf{5 . 0}$ & $\mathbf{2 . 0}$ vs $\mathbf{5 . 0}$ \\
\hline 1.50 & $1.06(0.72,1.57)$ & $1.32(0.75,2.31)$ & $1.90(1.06,3.41)$ \\
1.75 & $1.15(0.94,1.41)$ & $1.56(1.17,2.07)$ & $2.46(1.76,3.43)$ \\
2.00 & $1.23(1.02,1.49)$ & $1.77(1.36,2.30)$ & $2.98(2.15,4.14)$ \\
2.25 & $1.29(1.04,1.60)$ & $1.96(1.45,2.65)$ & $3.47(2.27,5.30)$ \\
2.50 & $1.34(1.07,1.70)$ & $2.12(1.50,3.00)$ & $3.92(2.24,6.88)$ \\
All & $1.25(1.05,1.50)$ & $1.76(1.36,2.27)$ & $2.76(2.02,3.77)$
\end{tabular}

$O R$, odds ratio; $G O A$, geometric orifice area; $B S A$, body surface area. 
TABLE 5. Adjusted ORs for EOA at selected values of BSA

\begin{tabular}{lccrr}
\hline & \multicolumn{3}{c}{ EOA $\left(\mathbf{c m}^{2}\right)$} \\
\cline { 2 - 5 } BSA & $\mathbf{1 . 7 5}$ vs $\mathbf{2 . 0}$ & $\mathbf{1 . 5}$ vs $\mathbf{2 . 0}$ & $\mathbf{1 . 2 5}$ vs 2.0 & $\mathbf{1 . 0}$ vs 2.0 \\
\hline 1.50 & $1.02(0.92,1.14)$ & $1.17(0.95,1.43)$ & $1.49(1.10,2.02)$ & $2.13(1.37,3.30)$ \\
1.75 & $1.09(1.03,1.16)$ & $1.30(1.15,1.47)$ & $1.68(1.38,2.04)$ & $2.35(1.75,3.17)$ \\
2.00 & $1.13(1.06,1.19)$ & $1.35(1.21,1.52)$ & $1.73(1.42,2.11)$ & $2.38(1.74,3.24)$ \\
2.25 & $1.14(1.06,1.22)$ & $1.36(1.16,1.60)$ & $1.72(1.29,2.30)$ & $2.30(1.46,3.62)$ \\
2.50 & $1.14(1.03,1.26)$ & $1.35(1.08,1.70)$ & $1.68(1.12,2.52)$ & $2.19(1.16,4.10)$ \\
All & $1.12(1.06,1.18)$ & $1.34(1.20,1.50)$ & $1.72(1.43,2.06)$ & $2.36(1.78,3.13)$
\end{tabular}

ORs, odds ratios; $E O A$, effective orifice area; $B S A$, body surface area.

and labeled size, increasing degrees of "mismatch" as defined by decreasing the ratio of EOA/BSA or GOA/BSA is generally associated with better outcomes, not worse outcomes. Point estimates from the model containing GOA (Figure 3) suggest that the trend may reverse itself when BSA is greater than about 2.0; that is, BSA may exhibit a U-shape relationship with operative mortality. These results are potentially provocative, suggesting that in the small fraction of patients with extremely small GOA and large BSA, patient prosthesis mismatch may become an important phenomenon. From a statistical point of view, however, our analysis yielded no significant evidence of an interaction between the internal orifice size of the valve implanted (using GOA or projected in vivo EOA as an index) and the shape of the curve relating BSA to mortality. Moreover, the apparent upturn in mortality disappeared when the nonsignificant ratio terms (GOA/BSA and $\mathrm{GOA}^{2} / \mathrm{BSA}^{2}$ ) were removed from the logistic regression model.

\section{Discussion}

Our study provides strong evidence of a clinically meaningful association between indices of prosthesis internal

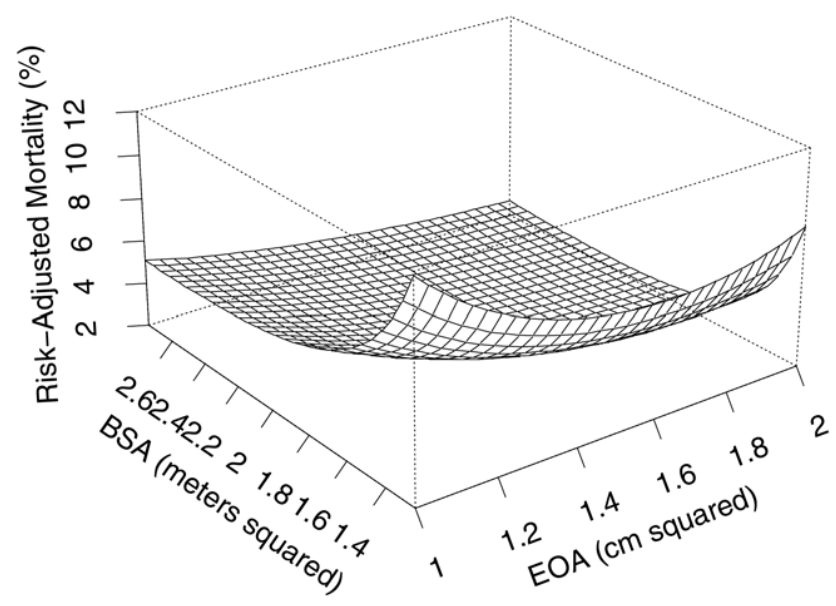

Figure 1. Estimated risk-adjusted mortality rate as a function of $B S A$ and EOA. BSA, body surface area; EOA, effective orifice area. orifice size and operative mortality. It does not indicate that the observed association is causal or dependent on the patient's BSA. Although it is impossible to test this hypothesis directly, the higher mortality associated with low EOA/ $\mathrm{BSA}$ or GOA/BSA ratios is usually presumed to result from worse hemodynamic performance of valves that have an internal orifice size that is too small relative to the size of

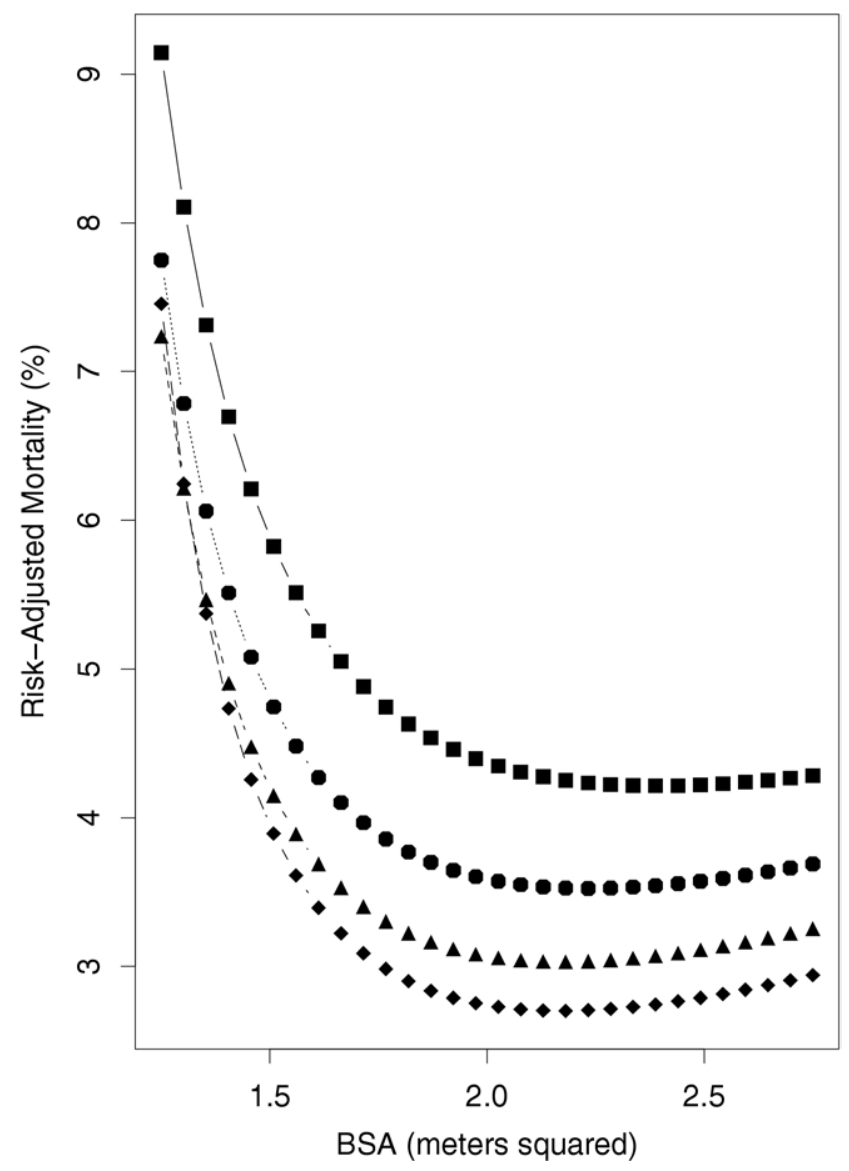

Figure 2. Estimated association between BSA and risk-adjusted mortality as a function of EOA. $\square, E O A=1.2 \mathrm{~cm}^{2} ; O, E O A=1.4$ $\mathrm{cm}^{2} ; \triangle, E O A=1.6 \mathrm{~cm}^{2} ;, E O A=1.8 \mathrm{~cm}^{2} . B S A$, body surface area; $E O A$, effective orifice area. 


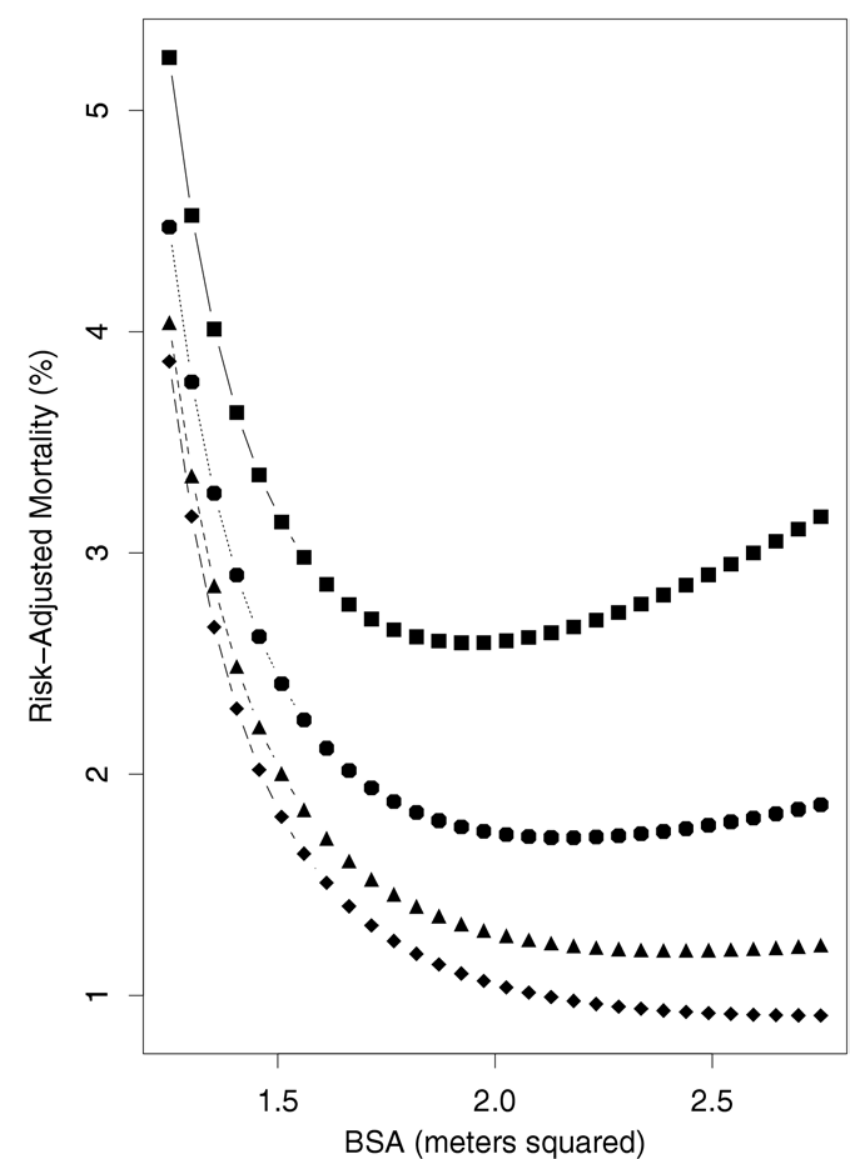

Figure 3. Estimated association between BSA and risk-adjusted mortality as a function of GOA. $\square, \mathrm{GOA}=2.0 \mathrm{~cm}^{2} ; O, \mathrm{GOA}=3.0$ $\mathrm{cm}^{2} ; \triangle, \mathrm{GOA}=4.0 \mathrm{~cm}^{2} ; \triangle, \mathrm{GOA}=5.0 \mathrm{~cm}^{2}$ ). BSA, body surface area; $G O A$, geometric orifice area.

the patient. Underpinning this assumption is the hypothesis that if an excessive amount of energy is expended by the left ventricle to pump blood across such a valve, there will be a detrimental impact on operative mortality and that because cardiac output increases linearly with BSA, the effect should become more pronounced as BSA increases for a given prosthesis internal orifice size. Unlike other investigators, ${ }^{3-8}$ in our multivariable analyses, we did not assume a priori that EOA or GOA should be considered only in relation to BSA. In addition, our analysis allowed for the possibility that BSA might have its own independent effect on mortality, quite apart from considerations related to prosthesis internal orifice size. The main finding of these analyses was that the magnitudes of the associations between our proxy measures of prosthesis internal orifice size (EOA and GOA) and mortality do not vary substantially depending on the patient's BSA. Thus although there are numerous possible explanations for this negative finding, we do not feel that the interaction between patient size and prosthesis internal orifice size is the driving force for the observed association between prosthesis internal orifice size and operative mortality in the present study. This conclusion is reflected by the lack of significance of EOA/BSA or GOA/BSA in models that include EOA or GOA, respectively.

The notion of prosthesis-patient mismatch implies that for a fixed valve model and manufacturer's labeled valve size, and holding all other factors constant, patients with larger BSA will have worse outcomes than patients with small BSA. In fact, we found no evidence of worse outcomes among patients with larger BSA after stratification by prosthesis internal orifice size as defined by EOA or GOA. On the contrary, larger BSA (ie, lower EOA/BSA) was generally associated with lower operative mortality regardless of the valve model and manufacturer's labeled valve size inserted. This finding is consistent with the interpretation that unmeasured confounder variables that lead to a protective effect of increasing BSA appear to be more important determinants of operative mortality than what others have called "mismatch."

When BSA is held constant, we found that mortality appears to increase with decreasing values of EOA. Although it is also true that mortality increases as a function of EOA/BSA (treating BSA is a constant), we did not find compelling statistical evidence to support using EOA/BSA as a criterion for valve selection. In fact, because the ratio term EOA/BSA is nonsignificant in a model that includes EOA and 1/BSA as main effects, there is no evidence to conclude that the relationship between EOA and mortality depends on the patient's BSA. Therefore, our data do not provide support for the convention of measuring EOA/BSA and using specific cutoffs in an effort to decrease operative mortality.

Taking a balanced interpretation of our results, it is important to note that our results also cannot exclude a significant causal mechanism related to hemodynamics ("mismatch") in a subset of patients. The lack of interaction between indices of prosthesis internal orifice size and BSA may be due to measurement error, the use of imperfect proxy variables, or unmeasured confounder variables. Nonetheless, it appears that the potential negative effects of poor hemodynamic performance of valves with small EOA or GOA may be overwhelmed by the operative mortality advantage of larger BSA. We can speculate that the apparent independent protective effect of increasing BSA may simply reflect relative ease of valve implantation in patients with larger aortic annuli and an attendant decrease in technically related complications. We did not find any clear cutoff values for EOA that are acceptable or unacceptable. Other than the dependence on EOA, we also did not find a consistent independent relationship of the type of valve by 
manufacturer on operative mortality. Our data neither refute nor confirm the contention ${ }^{3-5}$ that GOA, because of its robustness, is preferable to projected in vivo EOA as a practical preoperative index of prosthesis internal orifice size.

\section{Conclusions}

Unlike our own analysis, Blais and colleagues ${ }^{6}$ included patients who had AVR combined with CABG. Because we limited ourselves to patients with isolated AVR, we cannot exclude the possibility that in patients with impaired left ventricular function ${ }^{35}$ or coronary artery disease, prosthesispatient mismatch may be a clinically important phenomenon, hypothetically as a result of concerns related to the energy supply-demand ratio. We would predict that this might occur more commonly in large patients (high energy demand) with small prostheses (greater myocardial energy loss with ejection) when combined with flow-limited oxygen delivery to the left ventricular myocardium due to both prolonged global ischemia and residual coronary ischemia after revascularization. Furthermore, our study provides no insight into the potential negative impact of aortic prostheses with small internal orifice area on left ventricular mass regression or on long-term mortality. ${ }^{36,37}$

In the version of the STS software available during this study, the type of St Jude valve was not specified, and the EOA values used were those for standard (rather than high profile [HP] or Regent) models. The Regent model was not even available during the first 2 years of our study interval, and it likely was used in a very small proportion of our study group patients. In other studies, ${ }^{3}$ the HP model represented only $6 \%$ of St Jude mechanical valves. Therefore, we estimate that approximately $90 \%$ of the patients did in fact have the standard model St Jude valve. We repeated the analysis excluding all St Jude valves (Tables E5 and E6) and the conclusions did not change.

In summary, these data clearly demonstrate that small prosthesis internal orifice size is associated with an increase in operative mortality after isolated AVR. Our study does not provide an explanation for this finding. Although technical factors may be 1 possibility, we cannot exclude the possibility that worse hemodynamics are associated with smaller prosthesis size. Because operative mortality decreases in general as BSA increases for a given EOA or GOA, our results suggest that the protective effect of increased BSA may confound the impact of any potential negative hemodynamic effect of small EOA or small GOA. We find that given EOA or GOA alone as covariates, EOA/BSA and GOA/BSA are not significant predictors of operative mortality in multivariable models. We do not advocate the practice of using arbitrary cutoff values of EOA/BSA as a decision tool to determine the type or manufacturer's labeled size of valve to be utilized in a given patient in an attempt to decrease operative mortality. In terms of selecting the type of valve or technique of valve replacement, we believe that primary consideration should be given to factors such as durability, surgeon experience, technical ease, and speed of implantation and factors influencing the choice of a bioprosthesis over a mechanical valve and vice versa. Once these factors have been considered, our data do suggest that it may be reasonable to give preference to valves with consistently higher projected in vivo EOA or GOA values. Without confirmatory randomized trial data to mitigate unmeasured confounder variables, there is insufficient data to validate the practice of using the EOA/BSA ratio as a method for selecting the valve to be used in a given patient.

\section{References}

1. Rahimtoola SH. The problem of valve prosthesis patient mismatch. Circulation. 1978;58:20-4.

2. Rahimtoola SH, Murphy E. Valve prosthesis-patient mismatch. A long-term sequela. Br Heart J. 1981;3:331-5.

3. Blackstone EH, Cosgrove DM, Jamieson WRE, et al. Prosthesis size and long-term survival after aortic valve replacement. $J$ Thorac Cardiovasc Surg. 2003;126:783-96.

4. Gillinov AM, Blackstone EH, Rodriguez LL. Prosthesis-patient size: measurement and clinical implications. J Thorac Cardiovasc Surg. 2003;126:313-6.

5. Medalion B, Blackstone EH, Lytle BW, White J, Arnold JH, Cosgrove DM. Aortic valve size: is valve size important? J Thorac Cardiovasc Surg. 2000;119:963-74.

6. Blais C, Dumesnil JG, Baillot R, Simard S, Doyle D, Pibarot P. Impact of valve prosthesis-patient mismatch on short-term mortality after aortic valve replacement. Circulation. 2003;108:983-8.

7. Pibarot P, Dumesnil FG. Hemodynamic and clinical impact of prosthesis-patient mismatch in the aortic valve position and its prevention. J Am Coll Cardiol. 2000;36:1131-41.

8. Pibarot P, Dumesnil JG, Cartier PC, Metras J, Lemieux MD. Patientprosthesis mismatch can be predicted at the time of operation. Ann Thorac Surg. 2001;71:265-8.

9. Rao V, Jamieson WRE, Ivanov J, Armstrong S, David TE. Prosthesispatient mismatch affects survival after aortic valve replacement. Circulation. 2000;102(suppl III):III5-9.

10. Hanayama N, Christakis GT, Mallidi HR, et al. Patient prosthesis mismatch is rare after aortic valve replacement: valve size may be irrelevant. Ann Thorac Surg. 2002;73:1822-9.

11. Autschbach R, Walther T, Falk V, Kostelka M, Rosler A, Langebartels $\mathrm{G}$, et al. Prospectively randomized comparison of different mechanical aortic valves. Circulation. 2000;102(19 suppl 13):III1-4.

12. Walther T, Falk V, Langebartels G, Kruger M, Bernhardt U, Diegeler $\mathrm{A}$, et al. Prospectively randomized evaluation of stentless versus conventional biological aortic valves: impact on early regression of left ventricular hypertrophy. Circulation. 1999;100(19 suppl):II-6-10.

13. David TE, Puschmann R, Ivanov J, Bos J, Armstrong S, Feindel CM, et al. Aortic valve replacement with stentless and stented porcine valves: a case-match study. J Thorac Cardiovasc Surg. 1998;116:236-41.

14. Cohen G, Christakis GT, Joyner CD, et al. Are stentless valves hemodynamically superior to stented valves? A prospective randomized trial. Ann Thorac Surg. 2002;73:767-8.

15. Ruel M, Rubens FD, Masters RG, Pipe AL, Bedard P, Hendry PJ, et al. Late incidence and predictors of persistent or recurrent heart failure in patients with aortic prosthetic valves. $J$ Thorac Cardiovasc Surg. 2004;127:149-59.

16. Capps SB, Elkins RC, Fronk DM. Body surface area as a predictor of aortic and pulmonary valve diameter. $J$ Thorac Cardiovasc Surg. 2000;119:975-82.

17. Christakis GT, Buth KJ, Goldman BS, Fremes SE, Rao V, Cohen G, et al. Inaccurate and misleading valve sizing: a proposed standard for valve size nomenclature. Ann Thorac Surg. 1998;66:1198-203. 
18. Chambers JB, Oo L, Narracott A, Lawford PM, Blauth CI. Nominal size in six bileaflet mechanical aortic valves: a comparison of orifice size and biologic equivalence. J Thorac Cardiovasc Surg. 2003;125: 1388-93.

19. Garcia D, Pibarot P, Dumesnil JG, Sakr F, Durand LG. Assessment of aortic valve stenosis severity. A new index based on the energy loss concept. Circulation. 2000;101:765-71.

20. Flaschskampf FA, Weyman AE, Guerrero JL, Thomas JD. Influence of orifice geometry and flow rate on effective valve area: an in vitro study. J Am Coll Cardiol. 1991;15:1173-80.

21. Badano L, Mocchegiani R, Bertoli D, et al. Normal echocardiographic characteristics of the Sorin Bicardon bileaflet prosthetic heart valve in the mitral and aortic positions. J Am Soc Echocardiogr. 1997;10:632-43.

22. Dumesnil JG, Honos GN, Lemieux M, Beauchemin J. Validation and applications of indexed aortic prosthetic valve areas calculated by Doppler echocardiography. J Am Coll Cardiol. 1990;16:637-43.

23. Barratt-Boyes BG. The timing of operation in valvular insufficiency. J Card Surg. 1987;2:435-52.

24. Pibarot P, Dumesnil JG, Jobin J, Cartier P, Honos G, Durand LG. Hemodynamic and physical performance during maximal exercise in patients with an aortic bioprosthetic valve: comparison of stentless versus stented bioprostheses. J Am Coll Cardiol. 1999;34:1609-17.

25. Ferguson TB Jr, Dziuban SW Jr, Edwards FH, Eiken MC, Shroyer AL, Pairolero PC, et al. The STS National Database: current changes and challenges for the new millennium. Ann Thorac Surg. 2000;69:680-91.

26. Welke KF, Ferguson TB Jr, Coombs LP, Dokholyan RS, Murray CJ, Schrader MA, et al. Validity of the Society of Thoracic Surgeons National Adult Cardiac Surgery Database. Ann Thorac Surg. 2004;77:1137-9.

27. Wang Y, Moss J, Thisted R. Predictors of body surface area. J Clin Anesth. 1992;4:4-10.

28. Chambers J, Cross J, Deverall P, Sowton E. Echocardiographic description of the Carbomedics bileaflet prosthetic heart valve. J Am Coll Cardiol. 1993;21:398-405

29. Chafizadeh ER, Zoghbi WA. Doppler echocardiographic assessment of the S. Jude medical prosthetic valve in the aortic position using the continuity equation. Circulation. 1991;83:213-23.

30. Salomon NW, Okies JE, Krause AH, Page US, Bigelow JC, Colburn LQ. Serial follow-up of an experimental bovine pericardial aortic bioprosthesis: usefulness of pulsed Doppler echocardiography. Circulation. 1991;84(suppl III):III140-4.

31. Thomson DJ, Jamieson WRE, Dumesnil JG, et al. Medtronic mosaic porcine bioprosthesis: satisfactory early clinical performance. Ann Thorac Surg. 1998;66(suppl S):S122-5.

32. Dumesnil JG, LeBlanc MH, Cartier P, et al. Hemodynamic features of the freestyle aortic bioprosthesis compared with stented bioprosthesis. Ann Thorac Surg. 1998;66(suppl S):S130-3.

33. Gerdts E, Stangeland L, Engedal H, Nordrehaug JE. Postoperative Doppler echocardiographic evaluation in different sizes of MedtronicHall, Biocor and Carepentier-Edwards S.A.V. prosthetic aortic valves. Scand J Thorac Cardiovasc Surg. 1994;28:25-9.

34. David TE, Armstrong S, Sun Z. Clinical and hemodynamic assessment of the Hancock II bioprosthesis. Ann Thorac Surg. 1992;54: 661-8.

35. Ruel M, Al-Faleh H, Kulik A, Chan KL, Mesana TG, Burwash IG. Prosthesis-patient mismatch after aortic valve replacement predominantly affects patients with preexisting left ventricular dysfunction: effect on survival, freedom from heart failure, and left ventricular mass regression. J Thorac Cardiovasc Surg. 2006;131: 1036-44.

36. Tasca G, Mhagna Z, Perotti S, Centurini PB, Sabatini T, Amaducci A, et al. Impact of prosthesis-patient mismatch on cardiac events and midterm mortality after aortic valve replacement in patients with pure aortic stenosis. Circulation. 2006;113:570-6.

37. Molity-Echahidi D, Malouf JF, Girard SE, Schaff HV, Grill DE, Enriquez-Sarano ME, et al. Impact of prosthesis-patient mismatch on long-term survival in patients with small St. Jude Medical mechanical prostheses in the aortic position. Circulation. 2006;113:420-6.

\section{Discussion}

Dr George T. Christakis (Toronto, Canada). The authors are to be congratulated for this work, which adds substantially to the knowledge base of aortic valvular prosthesis size and its purported influence on operative mortality. The authors have used contemporary data from a homogenous population undergoing aortic valve replacement. The cohort is large with good statistical predictive power. Dr. Bridges and his colleagues performed multivariable analyses and demonstrated that effective orifice area or indexed effective orifice area, but not both, were independent predictors of operative mortality following aortic valve replacement.

We in Toronto have previously published data confirming an increase in operative mortality following aortic valve replacement when the indexed effective orifice area is less than $0.6 \mathrm{~cm}^{2} / \mathrm{m}^{2}$. We demonstrated operative mortalities of $2.1 \%$ versus less than $1 \%$ depending on whether they were above or below $0.6 \mathrm{~cm}^{2} / \mathrm{m}^{2}$. We also demonstrated that an indexed effective orifice area less than $0.6 \mathrm{~cm}^{2} / \mathrm{m}^{2}$ represented the 10th percentile for patient prosthesis size. This is, coincidentally, the exact cutoff Dr Bridges and colleagues have used to represent the lowest indexed effective orifice area.

In model 3, where both effective orifice area and indexed effective orifice area were used together in the model, the authors demonstrated that indexed effective orifice area did not predict operative mortality and only an effective orifice area less than 1.15 $\mathrm{cm}^{2}$ barely predicted operative mortality, with a lower-end confidence interval for an OR of 1.04 .

Do Dr Bridges and colleagues believe that perhaps effective orifice area is not a predictor of operative mortality but rather a clinical correlate or a confounding variable or a proxy variable that truly predicts operative mortality?

The small valve implant may not have been the cause of death. This introduces a plethora of questions. Were other variables or interactions of other variables tested in the models? What was the predictive value in the authors' best model based on a receiving operating characteristics curve? Could left ventricular function, gender, or valve lesion be a proxy for effective orifice area? And I am sure many of the sponsoring manufacturers would like to know whether the type and make of valve influenced the operative mortality.

Finally, the authors conclude that a small prosthesis size increases operative mortality following AVR, presumably on the basis of patient-prosthesis mismatch theory, but I believe on the basis of this conclusion that they do not think that the cause is hemodynamic. An alternative explanation may be that the operative mortality is increased by the complications associated with implanting any valve into a small annulus. Obstruction of coronaries, the need to perform aortoplasties or annuloplasties, paravalvular leaks, and tearing of the aorta from tying in a small hole are more common in patients with small annuli and friable tissues that usually occur in patients like this.

We caution the authors that conclusions that insinuate it is the small prosthesis that increases operative mortality rather than the small annulus may become a self-fulfilling prophecy. Concerted attempts to stuff even larger valves into small annuli may cause complications such as torn aortas and obstructed coronaries. Surgeons may be compelled to perform aortic root enlargement procedures or other complicated procedures with an accompanying 
higher operative mortality under the false impression that it is the small valve that is causing a higher operative mortality.

We suggest that further study is necessary to understand how small aortic annuli increase operative mortality, what the mechanism of complications is, and what techniques can be used to decrease the complication rate rather than focusing on the size of the implanted prosthesis. Do the authors know the mechanism of operative mortality in their patients, and what was the incidence of aortic root enlargement or aortoplasties?

Dr. Charles R. Bridges (Philadelphia, $\mathrm{Pa}$ ). Thank you very much, Dr. Christakis, for those insightful questions. I will try to answer each of them. You asked whether effective orifice area is nothing more than a clinical correlate or a proxy variable for some other variable that is actually the cause of increased mortality. We don't know the answer to that, but we believe that effective orifice area itself is not likely to be the most important variable, and in fact, we actually agree very much with you that small prosthesis size may be a surrogate or a proxy for small annular size and the technical issues associated with implanting valves in relatively small annuli.
In terms of whether there is a relationship of the type and make of valve, there is a slight difference in mortality for mechanical prostheses compared to bioprostheses; however, we could not find any consistent relationship by manufacturer of mortality, and obviously that was not the primary purpose of this study.

The other point you made was that it probably is the small annulus that is the cause of increased mortality associated with small prostheses, not the size of the prosthesis itself. Our analysis suggests that hemodynamics is not an important factor in the increased mortality associated with these small valves. If it were, we would have expected that the mortality would have gotten even higher when small valves were placed in larger patients. In fact, we did not find that to be the case, which underlines and echoes your point that it may have little to do with hemodynamics.

And I wholeheartedly agree with your assertion that an attempt to put larger valves in small patients, simply based on arbitrary cutoffs, may actually do more harm than good, although that would need to be the subject of an additional study, ideally, a randomized trial. 
TABLE E1. Adjusted ORs for GOA at selected values of BSA (limited to manufacturer's labeled valve sizes 19 and 21)

\begin{tabular}{lccr}
\hline & & $\mathbf{G O A}\left(\mathbf{c m}^{2}\right)$ & $\mathbf{2 . 0}$ vs $\mathbf{2 . 5}$ \\
\cline { 2 - 4 } BSA & $\mathbf{2 . 2 5}$ vs $\mathbf{2 . 5}$ & $1.17(0.91,1.50)$ & $\mathbf{1 . 7 5}$ vs $\mathbf{2 . 5}$ \\
\hline 1.50 & $1.08(0.97,1.20)$ & $1.26(1.00,1.58)$ & $1.27(0.81,1.98)$ \\
1.75 & $1.12(1.02,1.24)$ & $1.33(1.02,1.73)$ & $1.41(0.95,2.10)$ \\
2.00 & $1.15(1.03,1.29)$ & $1.38(0.96,1.98)$ & $1.53(0.96,2.43)$ \\
2.25 & $1.18(1.01,1.37)$ & $1.42(0.88,2.31)$ & $1.62(0.86,3.04)$ \\
2.50 & $1.19(0.97,1.47)$ & $1.23(0.98,1.53)$ & $1.69(0.74,3.89)$ \\
All & $1.11(1.01,1.22)$ & & $1.35(0.91,1.99)$ \\
\hline
\end{tabular}

ORs, odds ratios; $G O A$, geometric orifice area; $B S A$, body surface area.

TABLE E2. Adjusted ORs for EOA at selected values of BSA (limited to manufacturer's labeled valve sizes 19 and 21)

\begin{tabular}{|c|c|}
\hline BSA & EOA $\left(\mathrm{cm}^{2}\right) 1.0$ vs 1.25 \\
\hline 1.50 & $0.85(0.44,1.66)$ \\
\hline 1.75 & $0.80(0.43,1.52)$ \\
\hline 2.00 & $0.84(0.43,1.65)$ \\
\hline 2.25 & $0.92(0.39,2.15)$ \\
\hline 2.50 & $1.02(0.33,3.10)$ \\
\hline All & $0.86(0.46,1.60)$ \\
\hline
\end{tabular}

$O R$, odds ratios; $E O A$, effective orifice area; $B S A$, body surface area. 
TABLE E3. Adjusted ORs for GOA at selected values of BSA (limited to patients with BMI $<30 \mathrm{~kg} / \mathrm{m}^{2}$ )

\begin{tabular}{lccr}
\hline & & $\mathbf{G O A}\left(\mathbf{c m}^{\mathbf{2}}\right)$ & $\mathbf{2 . 0}$ vs $\mathbf{5 . 0}$ \\
\cline { 2 - 4 } $\mathbf{B S A}$ & $\mathbf{4 . 0}$ vs $\mathbf{5 . 0}$ & $\mathbf{3 . 0}$ vs $\mathbf{5 . 0}$ & $1.78(0.90,3.50)$ \\
1.50 & $1.13(0.71,1.79)$ & $1.37(0.71,2.64)$ & $2.13(1.47,3.11)$ \\
2.00 & $1.11(0.89,1.40)$ & $1.43(1.04,1.97)$ & $2.64(1.70,4.09)$ \\
2.25 & $1.14(0.91,1.44)$ & $1.58(1.15,2.16)$ & $3.26(1.71,6.19)$ \\
2.50 & $1.19(0.91,1.55)$ & $1.76(1.19,2.60)$ & $3.96(1.63,9.62)$ \\
All & $1.24(0.92,1.66)$ & $1.96(1.21,3.16)$ & $2.24(1.55,3.25)$ \\
\hline
\end{tabular}

ORs, odds ratios; $G O A$, geometric orifice area; $B S A$, body surface area; $B M I$, body mass index.

TABLE E4. Adjusted ORs for EOA at selected values of BSA (limited to patients with BMI $<30 \mathrm{~kg} / \mathrm{m}^{2}$ )

\begin{tabular}{lccrr}
\hline & \multicolumn{3}{c}{ EOA $\left(\mathbf{c m}^{2}\right)$} \\
\cline { 2 - 5 } BSA & $\mathbf{1 . 7 5}$ vs $\mathbf{2 . 0}$ & $\mathbf{1 . 5}$ vs $\mathbf{2 . 0}$ & $\mathbf{1 . 2 5}$ vs $\mathbf{2 . 0}$ & $\mathbf{1 . 0}$ vs $\mathbf{2 . 0}$ \\
\hline 1.50 & $0.99(0.87,1.12)$ & $1.08(0.85,1.37)$ & $1.31(0.92,1.87)$ & $1.75(1.04,2.93)$ \\
1.75 & $1.10(1.02,1.18)$ & $1.28(1.11,1.48)$ & $1.58(1.26,1.98)$ & $2.08(1.48,2.92)$ \\
2.00 & $1.15(1.06,1.25)$ & $1.37(1.16,1.62)$ & $1.68(1.26,2.25)$ & $2.14(1.35,3.39)$ \\
2.25 & $1.17(1.04,1.32)$ & $1.40(1.08,1.81)$ & $1.69(1.07,2.66)$ & $2.07(1.00,4.26)$ \\
2.50 & $1.18(1.00,1.38)$ & $1.39(0.96,2.00)$ & $1.64(0.86,3.11)$ & $1.94(0.71,5.26)$ \\
All & $1.12(1.04,1.20)$ & $1.31(1.14,1.50)$ & $1.61(1.29,2.01)$ & $2.08(1.48,2.93)$ \\
\hline
\end{tabular}

$O R s$, odds ratios; $E O A$, effective orifice area; $B S A$, body surface area; $B M I$, body mass index.

TABLE E5. Adjusted ORs for GOA at selected values of BSA (excluding St Jude valves)

\begin{tabular}{lccr}
\hline & & $\mathbf{G O A}\left(\mathbf{c m}^{\mathbf{2}}\right)$ & $\mathbf{3}$ \\
\cline { 2 - 4 } BSA & $\mathbf{4 . 0}$ vs $\mathbf{5 . 0}$ & $\mathbf{3 . 0}$ vs $\mathbf{5 . 0}$ & $\mathbf{2 . 0}$ vs $\mathbf{5 . 0}$ \\
\hline 1.50 & $1.03(0.67,1.57)$ & $1.35(0.75,2.43)$ & $2.27(1.22,4.22)$ \\
1.75 & $1.13(0.90,1.41)$ & $1.58(1.17,2.12)$ & $2.74(1.90,3.95)$ \\
2.00 & $1.19(0.97,1.46)$ & $1.73(1.31,2.27)$ & $3.04(2.05,4.52)$ \\
2.25 & $1.23(0.98,1.55)$ & $1.82(1.31,2.54)$ & $3.24(1.79,5.86)$ \\
2.50 & $1.26(0.99,1.61)$ & $1.89(1.24,2.88)$ & $3.36(1.44,7.85)$ \\
All & $1.18(0.98,1.44)$ & $1.68(1.29,2.19)$ & $2.86(2.01,4.05)$ \\
\hline
\end{tabular}

ORs, odds ratios; $G O A$, geometric orifice area; $B S A$, body surface area.

TABLE E6. Adjusted ORs for EOA at selected values of BSA (excluding St Jude valves)

\begin{tabular}{lccrr}
\hline & \multicolumn{5}{c}{ EOA $\left(\mathbf{c m}^{2}\right)$} \\
\cline { 2 - 5 } BSA & $\mathbf{1 . 7 5}$ vs $\mathbf{2 . 0}$ & $\mathbf{1 . 5}$ vs $\mathbf{2 . 0}$ & $\mathbf{1 . 2 5}$ vs $\mathbf{2 . 0}$ & $\mathbf{1 . 0}$ vs $\mathbf{2 . 0}$ \\
\hline 1.50 & $0.97(0.81,1.18)$ & $1.10(0.80,1.51)$ & $1.44(0.95,2.17)$ & $2.18(1.27,3.71)$ \\
1.75 & $1.06(0.94,1.19)$ & $1.26(1.04,1.53)$ & $1.69(1.31,2.19)$ & $2.55(1.79,3.64)$ \\
2.00 & $1.10(0.99,1.23)$ & $1.34(1.12,1.61)$ & $1.81(1.40,2.33)$ & $2.68(1.82,3.95)$ \\
2.25 & $1.12(1,1.27)$ & $1.38(1.10,1.72)$ & $1.84(1.27,2.65)$ & $2.67(1.47,4.84)$ \\
2.50 & $1.13(0.98,1.30)$ & $1.38(1.03,1.86)$ & $1.82(1.08,3.08)$ & $2.59(1.11,6.06)$ \\
All & $1.09(0.98,1.21)$ & $1.32(1.11,1.57)$ & $1.75(1.38,2.22)$ & $2.58(1.84,3.62)$
\end{tabular}

$O R$, odds ratios; $E O A$, effective orifice area; $B S A$, body surface area. 